\title{
Havas-Lima o la inclusión del Perú en la red internacional de información del siglo XIX
}

Havas-Lima or Peru's inclusion in nineteenth century news network

Rhoda Desbordes Vela ${ }^{1}$

Universidad de Versalles Saint Quentin en Yvelines. Versalles, Francia

rhodavela@outlook.es

Citar como: Desbordes, R. (2018). Havas-Lima o la inclusión del Perú en la red internacional de información del siglo XIX. Desde el Sur, vol. 10, nro. 2, pp. 411-448.

\section{RESUMEN}

Este estudio histórico del desarrollo de las agencias internacionales de noticias en América del Sur tiene en cuenta especialmente la instalación de las grandes agencias internacionales en el subcontinente en general y en el Perú en particular. Este punto de vista ataca de entrada una idea preconcebida en la historiografía «agenciera». En efecto, la bibliografía existente destaca solo las sucursales de Buenos Aires y de Río de Janeiro, como los primeros y únicos focos de la presencia de la agencia francesa en Sudamérica. No obstante, otros puntos, y en momentos distintos, también contribuyeron a este primer impulso y a la materialización de una pequeña red de sucursales de las agencias mundiales. Uno de estos otros novedosos lugares de explotación es, evidentemente, la sucursal de Lima.

\section{PALABRAS CLAVE}

Havas, Reuters, agencias de noticias, periodismo, siglo XIX, Lima, Guerra del Pacífico

\section{ABSTRACT}

This historical study of the development of international news agencies in South America, takes into account

1 Doctora en Ciencias de la Información y de la Comunicación en la Universidad de París III Sorbonne-Nouvelle. Su trabajo se centra en el poder y los medios de comunicación y la historia de los medios de comunicación. Destaca, entre otros, Transnationales de l'information dans le Nouveau Monde. Les agences internationales de presse en Amérique du Sud, 1874-1919. 
their deployment in all the continent and, especifically in Peru. This paper criticizes a pre conceived concept in the «Agency» historiography. Indeed, the existing bibliography highlights only Buenos Aires and Rio de Janeiro branches, as the first and only foci of presence of Havas in South America. However, other locations, at different times, also contributed to its first impulse and development of a worldwide agencies small network of branches. One of these other novel places of development was the branch branch in Lima.

\section{KEYWORDS}

Havas, Reuters, news agencies, journalism, XIXth century, Lima, the War of the Pacific

\section{Introducción}

«Décidément l'Amérique [du] Sud constitue une page sombre dans I'histoire de l'exploitation de l'Agence Havas» ${ }^{2}$.

Henri Houssaye, director general de la Agencia francesa Havas, a Henri Gasser, director general de las sucursales y de los servicios en América del Sur (en Buenos Aires), París, 4 de abril de $1903^{3}$.

Con esta descorazonada sentencia, el director general de la Agencia Havas de París resume, a principios del siglo XX, la situación financiera a todas vistas catastrófica de una explotación informacional vieja de varios lustros. Una empresa deficitaria que, a pesar de sus vicisitudes e imprevistos, continúa entonces siendo un desafío para los dirigentes de la primera agencia de noticias del mundo, la francesa Havas, luego de casi 30 años de inversión.

En el ámbito de la historia de las transnacionales de la información, la región sudamericana y sus medios de comunicación han sido poco abordados por los académicos ${ }^{4}$. Sobre todo, los orígenes de una integración del continente sudamericano en el circuito internacional de las noticias son prácticamente desconocidos, a pesar de que el subcontinente estuvo en la mira de varias agencias internacionales de información durante todo el siglo XIX hasta bien entrado el siglo XX. Y en esta implantación, los logros de la agencia francesa Havas no pueden ser pasados por alto.

2 «Definitivamente, la explotación sudamericana constituye una página sombría en la historia de la agencia Havas».

3 Archives Nationales, 5 AR 38 (2), f. 100.

4 La investigación sobre los primeros medios de comunicación en América Latina es pobre en general (Bethell, 1995, p. 951). 
Las actividades de la agencia parisina en la región sudamericana se acomodan perfectamente a la cronología elaborada por Terhi Rantanen, historiadora de los medios globales. En la primera mitad del siglo, las grandes agencias europeas y norteamericanas comienzan a surgir: la francesa, Havas, fue creada en 1832, la norteamericana Associated Press en $1846^{5}$ y la británica Reuters, igual que la alemana Wolff, son fundadas en 1851.

Luego de nacer y copar sus respectivos mercados nacionales, estas agencias deciden conquistar el mundo entero. La segunda gran fase de su expansión, que los ve formar una suerte de cartel $^{6}$, se realiza a través de una serie de acuerdos y alianzas que les permiten dominar sus plazas internas, externas y especialmente extraeuropeas. Así, entre 1870 y 1914 (Rantanen, 1990, p. 13), las agencias europeas controlan de forma absoluta el mercado mundial de la información. Toda red que intente surgir, con ellos o sin ellos, debe lidiar obligatoriamente con los monopolios establecidos por una de estas tres o cuatro agencias ${ }^{7}$ en distintas partes del globo.

Este estudio histórico del desarrollo de las agencias internacionales de noticias en América del Sur tiene en cuenta especialmente la instalación de las grandes agencias internacionales en el subcontinente en general y en el Perú en particular. Este punto de vista ataca de entrada una idea preconcebida en la historiografía «agenciera». En efecto, la bibliografía existente destaca solamente las sucursales de Buenos Aires y de Río de Janeiro, como los primeros y únicos focos de la presencia de la agencia francesa en Sudamérica. No obstante, otros puntos, y en momentos distintos, también contribuyen a este primer impulso y a la materialización de una pequeña red de sucursales de las agencias mundiales. Uno de estos otros novedosos lugares de explotación es, evidentemente, la sucursal de Lima.

Heredera del virreinato más próspero de todas las posesiones españolas, la capital del Perú ve instalarse, en el transcurso de 1875, una sucursal dependiente de las dos más grandes agencias internacionales de información del momento: la francesa Havas y la británica Reuters ${ }^{8}$. Y es que es gracias a esta última que una primera actividad «agenciera» había surgido en América del Sur. El barón Julius de Reuter personalmente, a mediados del siglo XIX, organizó por primera vez una ingeniosa red de

5 «The final period, which started after World War II, marks the dominance of the post-war international agencies, Reuters, AP, United Press International (UPI), the French Agence France Press (AFP) and the Soviet Telegrafnoe agentstvo Sovetskogo Souiza (TASS)» (Rantanen, 1990, p. 13).

6 Los especialistas en agencias de prensa se refieren con esta denominación al bloque de agencias europeas, compuesto por Reuters, Havas y Wolff, que se formó a mediados del siglo XIX. En inglés el apelativo usual es «the Ring Combination».

7 La agencia norteamericana tenía en esta época un peso menor en el seno de esta concordia.

8 La agencia británica era conocida entonces como la Reuter's Telegram Company. 
agentes o corresponsales en este territorio. Así, si bien han sobrevivido en los archivos de la compañía Reuters de Londres ${ }^{9}$ ciertos documentos que registran la existencia de dicha red en esa época, no es difícil comprobar que las actividades de la agencia británica en Sudamérica son apenas visibles en los documentos que datan de la segunda mitad del siglo XIX.

\section{Sobre las fuentes}

Se vuelve entonces obligatorio revisar y apoyarse además en los documentos que provienen de la agencia Havas. En efecto, los archivos correspondientes a las primeras actividades de la agencia francesa, conservados en la sede Archivos Nacionales de Francia (Brot, 1969), en París, constituyen un corpus de base y son objeto de una preocupación de conservación y de metodología instructiva por parte de la Dirección General de la agencia fundada por Charles Havas. No obstante, este correo interno de los primeros años de explotación sudamericana presenta numerosas lagunas. El fondo documental que proviene de la antigua sede de la agencia en la calle Notre Dame des Victoires de París es desgraciadamente parcelario y data principalmente del último cuarto del siglo XIX.

Estos documentos, generalmente redactados por los directores de la agencia francesa (personal más administrativo que de redacción) en París, pueden ser clasificados en dos grandes categorías a pesar de sus notorias ausencias: primero, los que abundan más, pero que no son tan pertinentes para nuestro estudio, pues muestran la organización de Havas en América del Sur desde un punto de vista indirecto. Se trata de las cartas enviadas desde París a las sucursales extranjeras como Londres, Lisboa o Nueva York. El fondo documental dirigido a Londres es, de lejos, el más importante y, quizá, el más oportuno. En esta categoría se halla la correspondencia dirigida al socio de Havas, la agencia británica Reuters. Allí podemos ver las principales cuestiones que tratan de la administración del servicio informativo para Sudamérica desde 1875. El servicio para el subcontinente es abordado en este correo, pero no es el único tema de las misivas, evidentemente. A Londres también va dirigida una serie de cartas a la sucursal (Havas-Londres) que la agencia francesa tiene en las oficinas de Reuters a partir de $1884^{10}$.

En segundo lugar, contamos con los documentos menos numerosos, pero de gran valor para nosotros: los «copie de lettres» para cuatro sucursales

9 The Reuters Archive se encontraba en el 85 Fleet Street Londres EC4P 4AJ hasta mediados de 2005. Los documentos más útiles para nuestra investigación fueron notas de síntesis y los dossiers especiales, Minute Books, Telegram Books, Staff, Central Registry y la colección personal de Roderick Jones.

10 La sucursal Havas-Londres fue conocida en un principio como Bureau Amérique du Sud, cuyo correo debutó en 1875. Lamentablemente, ninguna huella del intercambio epistolar mantenido con esta oficina ha sobrevivido. 
sudamericanas que nos ofrecen los detalles del funcionamiento de casi toda la organización informacional para Sudamérica ${ }^{11}$. La mayor parte del tiempo se trata de dossiers, de aproximadamente quinientos folios cada uno, conteniendo las copias de las cartas, notas y memorándums enviados por los dirigentes de París, o por la oficina de Havas en Londres, a las sucursales sudamericanas.

El estilo de estos documentos es sumamente rígido y su naturaleza, netamente administrativa. No obstante, ellos son esenciales para comprender los primeros logros y la organización original de los servicios y las sucursales Havas en Sudamérica. El instrumento, aunque imperfecto ${ }^{12}$, elaborado por Isabelle Brot, es de este modo preciso para nuestra investigación. Este inventario nos envía igualmente, por ejemplo, a diversos tratados y contratos establecidos entre Havas y otras empresas de información, como otras agencias de noticias y demás compañías cablegráficas, sin dejar de lado los diarios y los Gobiernos sudamericanos.

En cuanto a los productos de redacción o informativos de la agencia, los despachos de noticias son inexistentes. No obstante, la colección microfilmada de la Correspondance Havas conservada en la Bibliothèque Nationale de Francia nos ha guiado en la comprensión de varios sucesos de fines del siglo XIX y principios del siglo XX. Uno de esos grandes acontecimientos es, sin duda, y por razones económicas, la Guerra del Pacífico, que, de 1879 a 1883, produce bastante materia prima informativa y ocasiona ciertas rectificaciones en la organización y en el funcionamiento de los servicios de noticias que la agencia Havas mantiene desde América del Sur para Europa. Este conflicto es igualmente interesante debido a que, por primera vez, debido a su forma imprevisible y novedosa, las cuestiones de «cobertura periodística» son puestas sobre el tapete y las agencias de prensa toman nuevas medidas para informar al resto del planeta sobre eventos que ocurren en el subcontinente americano. La guerra con Chile nos invita también a analizar los flujos y contenidos informacionales de este periodo.

11 De las nueve sucursales que vieron la luz a partir de 1874, solamente cuatro cuentan con archivos consultables según las fechas: la sucursal de Lima (1875-1887) con código 5 AR 57 (5); la sucursal de Pernambuco (1875-1882), con código 5 AR 118 (6); la sucursal de Buenos Aires (1881-1887), con código 5 AR 37 (1). Las cartas que la sucursal de Río de Janeiro envía a París comienzan en 1902 y terminan en 1940; salen así del marco temporal de este estudio (código 5 AR 123).

12 El inventario de los archivos de Havas omite un volumen de 500 folios («un copie de lettres») perteneciente a la sucursal de Montevideo para el periodo 1887-1896. En el «copie de lettres» correspondiente a la sucursal de Buenos Aires, y que comienza en 1881, hallamos también dos cartas dirigidas por París a la sucursal de Valparaíso. Las sucursales brasileñas de Para, Bahía y Santos no han dejado archivos. El expediente 5 AR 37 (2) inaugura, en Montevideo, un correo dirigido no a un agente o director de sucursal, sino al director general de los servicios y sucursales sudamericanas en su totalidad. Además, el inventario no suele mencionar la existencia de algunos suscriptores a la Feuille des Courriers de l'Amérique du Sud. 
Esta masa documental de orden administrativo, y, si se quiere, periodístico, encuentra su complemento en las indicaciones halladas en los archivos diplomáticos del Quai d'Orsay de París. Pues, a pesar de su carácter eminentemente privado, la agencia Havas mantiene a lo largo de su historia una relación privilegiada con el Gobierno francés. Esta intimidad halla su apogeo, claro está, con la llegada de la Primera Guerra Mundial ${ }^{13}$.

Cinco países «nuevos», cuatro republicas hispánicas y el Imperio del Brasil son escogidos para esta primera implantación sudamericana. El paisaje mediático de estos lares es tan homogéneo que la agencia francesa considera a la América meridional como una entidad territorial, comercial y política uniforme. Para realizar un análisis crítico del destino de la agencia francesa en un ambiente internacional dominado, en un primer momento, por el Reino Unido y, luego, por Estados Unidos ${ }^{14}$, hemos recurrido a la noción de la «era de los imperios». De allí, nuestro punto de vista predominantemente occidental, por no decir francés o europeocentrista.

Los movimientos transatlánticos entre Europa y el continente americano se intensifican a partir de la segunda mitad del siglo XIX. Es importante mencionar que las fronteras de este espacio se abren en ese momento al comercio, las inversiones extranjeras, y los flujos de capitales y los de la información. La transformación económica que comienza a mediados del siglo XIX y que se intensifica a partir de 1870 introduce a América del Sur al capitalismo mundial al mismo tiempo que el subcontinente presenta nuevas características demográficas, como la gran inmigración, especialmente europea, a partir de 1850, y nuevos contornos geopolíticos ${ }^{15}$. La hegemonía británica se encuentra en el centro de todo este desarrollo a través de operaciones comerciales y de inversión de capitales en la región, aunque también una primera influencia norteamericana se presenta en la región del Caribe.

Simultáneamente, las agencias de información viven su edad de oro y acentúan su expansión extraeuropea de acuerdo con los grandes avances

13 La serie Correspondencia Política en los Fondos Antiguos (1871-1896) contiene los despachos transmitidos o recibidos por el Ministerio de Relaciones Exteriores de las legaciones francesas en América del Sur. Todo está clasificado por país y por orden cronológico. Países como Argentina, Brasil, Chile, Perú y Uruguay mantienen relaciones diplomáticas en esta época. Los archivos diplomáticos conservan igualmente los Fondos Contemporáneos que nos han sido muy útiles, pero solamente a partir de 1896. Los documentos privados de los diversos agentes del ministerio en pleno ejercicio de sus funciones complementan los documentos ya mencionados.

14 La bibliografía agenciera hace referencia a las agencias Associated Press y United Press de Estados Unidos como las «agencias norteamericanas» o «americanas». Como aquí tratamos de América del Sur, preferimos utilizar mayormente los adjetivos «estadounidenses» y «norteamericanas».

15 Ver nuestro artículo sobre los movimientos migratorios trasatlánticos (Desbordes, 2005). 
en materia de telecomunicaciones que ocurren en el planeta. Rápidamente, el continente sudamericano se convierte en un objetivo a alcanzar y en el ente geoinformacional a construir y explotar.

\section{No todo es para Havas}

La instalación de las sucursales Havas-Reuters en diversas capitales sudamericanas obedece a una razón principal y a varias razones secundarias.

El argumento primordial es consecuencia de una serie de acuerdos entre las principales agencias internacionales de noticias de la época. Estas se «dividen el mundo» según ciertas zonas de influencia geopolítica de los países donde estas agencias tienen su sede principal. Pero, al mismo tiempo, este hecho nos ofrece una suerte de paradoja para el caso latinoamericano. El subcontinente no depende ni política ni «colonialmente» de Francia, ni de Inglaterra, ni de Alemania. Nada, aparentemente, acerca a Francia o Inglaterra a América del Sur, menos aún el elemento lingüístico. Entonces salen a la luz otros aspectos que la historiografía agenciera ha dejado de lado en más de una ocasión: los elementos económicos y culturales.

Para ello, hemos tenido que apoyarnos en los avances propuestos por el francés Denis Rolland, quien se ocupa de la historia cultural de las relaciones internacionales en general y de los lazos que mantiene América Latina con Europa en particular en los últimos 200 años.

Otra idea comúnmente aceptada entre los investigadores que trabajan en el desarrollo agenciero del siglo XIX mantiene que América del Sur fue siempre monopolio exclusivo de la agencia francesa, sin mayores obstáculos, durante más de medio siglo (Lefebure, 1992, p. 143). Aceptar esta idea sería ignorar seriamente la alianza que existió entre las dos agencias mundiales más poderosas de ese entonces, Havas y Reuters. Además, estaríamos dejando de lado el interés permanente que otras agencias de noticias o telegráficas, ajenas al cartel, equivalentes o menos importantes, y no siempre europeas ${ }^{16}$, mostraban hacia la región sudamericana, poniendo en jaque, por momentos, la preponderancia de Havas en la zona.

Desde 1856, las tres agencias internacionales más importantes del globo - Havas, Reuters y la alemana Woff, más tarde conocida también con el nombre de la Continental - se reparten el mundo mediante una serie de contratos y acuerdos (Rantanen, 1990, pp. 38-39). Esta división del

16 Como fue el caso de la agencia norteamericana Stuart, cuya presencia puede ser rastreada por esta época en Lima. 
mundo en tres esferas o zonas de influencia subsiste con grandes altibajos hasta bien entrado el siglo XX. En esta suerte de triunvirato, la predominancia de Havas y de Reuters es más que evidente hasta fines del siglo XIX.

Para 1859, Havas transmite a Wolff (como lo hace desde algún tiempo para Reuters) sus telegramas desde Francia, España, Italia y las naciones del Levante. En contrapartida, la agencia alemana le envía telegramas de Alemania, Rusia, los países eslavos y Escandinavia. A Reuters le corresponde, indiscutiblemente, todas las zonas a donde se extiende el Imperio británico. Esta distribución del mercado mundial de la información supone una inviolabilidad de territorios sumamente restrictiva y fuente de diversos litigios y fricciones entre estos y otros socios.

\section{La alianza Havas-Reuters para América del Sur}

A mediados del siglo XIX, las posesiones territoriales de Havas incluyen entonces diversos Estados de Europa occidental, central y oriental. América del Sur, en aquel tiempo, digna heredera de un pasado colonial a todas luces evidente, constituye una zona clave para establecer su superioridad y la agencia francesa decide convertirla en uno de sus puntos estratégicos. Pero el impulso económico de la región atrae igualmente a otra agencia europea que desea incluir Sudamérica entre sus zonas de influencia fuera del Viejo Continente.

Para el subcontinente, Havas y Reuters idean una política de implantación novedosa y razonable y el apoyo financiero de Reuters en este prometedor proyecto es primordial. La presencia de ambas agencias en Sudamérica es una de las razones principales del acuerdo denominado Joint Purse Agreement (contrato de fusión de intereses) del 4 de noviembre de 1869. Propuesto en un principio por Reuters a Havas, este tratado específico es un acuerdo, casi secreto, de explotación común en el mundo entero, con beneficios y pérdidas a partes iguales.

El segundo acuerdo entre Havas y Reuters, que data del primero de mayo de 1874 , es que el establece realmente en común «todos los servicios telegráficos presentes y futuros, tanto en lo que concierne la explotación de noticias políticas, financieras y comerciales, industriales y generales del mundo entero, como en lo que respecta a la transmisión de los telegramas privados y fraccionados del globo, de forma que cada una de las partes [la Reuter's Telegram Company y la sociedad Havas Laffite et Compagnie] tendrá derecho como antes a la mitad de los beneficios de esta doble explotación común, de la misma forma que ella hará frente a 
la mitad de las pérdidas que resulten de los asuntos sociales» ${ }^{17}$. De esta manera, todos los gastos son divididos de forma equitativa entre las dos agencias europeas.

Como ya lo habíamos mencionado, desde 1860 por lo menos (Desmond, 1978, p. 249) la agencia Reuters cuenta con un corresponsal en Río de Janeiro. Julius de Reuter organiza, entre América del Sur, las Antillas, Estados Unidos y Londres, una red que le sirve para la transmisión de los despachos privados. Desgraciadamente, conservar esta pequeña red significa la manutención de una oficina sumamente costosa en Nueva York (Frederix, 1959, p. 140).

Pero si no tenemos en cuenta a los corresponsales de agencias - sobre todo los ya señalados de Reuters - activos en la zona desde mediados del siglo XIX, 1874 ve inaugurar de forma «oficial» la historia de las agencias de información en Sudamérica. Desde principios de ese año, funciona igualmente el cable submarino que une la ciudad brasileña de Pernambuco con Londres (a través del puerto de Falmouth) desde el fondo del Atlántico.

El Joint Purse Agreement firmado en $1874^{18}$ por Havas y Reuters inaugura un funcionamiento agenciero que comporta diversos servicios. En París, luego del deceso del hijo menor del fundador de la agencia, Charles Havas, Auguste Havas, Edouard Lebey toma las riendas de la sociedad Havas-Laffite. Luego la dirección llega a las manos de Henri Houssaye, amigo personal de Lebey y abogado de formación, quien asume la secretaría general. Todas las sucursales y todos los servicios agencieros en América del Sur dependen de la dirección parisina, al menos en un principio, aunque luego se hace necesaria la apertura de la oficina Amérique Sud en Londres, porque esta ciudad es el punto de partida del cable transatlántico.

El francés Elie Mercadier, verdadero corresponsal de prensa con el correr de los años, es nombrado director de este proyecto y es el encargado de crear y organizar las sucursales y los servicios para el subcontinente, e instalar las primeras nueve sucursales en las dos costas sudamericanas. Tanto los puertos como las rutas comerciales del «comercio libre» establecidos por las coronas ibéricas a partir de la segunda mitad del siglo XV son escogidos, tres siglos después, para ser puntos de partida de la «invasión» Havas-Reuters.

17 Archivos Nacionales, 5 AR 411, traducción de la autora.

18 Se trata de un segundo tratado firmado entre Havas y Reuters, pues el primero fue firmado en 1869. 
Para abrir estas sucursales, las agencias siguen en cierta forma el trazo administrativo de los antiguos colonizadores. Las nueve oficinas o sucursales cumplen funciones comerciales para los Imperios español y portugués. En Brasil, son cinco: Para (hoy la ciudad de Belém), Pernambuco (hoy Recife), Salvador de Bahía, Río de Janeiro y Santos. Todas antiguas capitanías existentes desde el siglo XVI.

En lo que concierne a la América española, la aparición de sucursales se hace consecutivamente de los dos lados del Atlántico. Primero, las de la región de La Plata, en Montevideo y en Buenos Aires. Enseguida, Valparaíso y Lima. Siguiendo aparentemente el sentido inverso de las agujas del reloj y comenzando por el noreste brasileño, a partir de 1874 las agencias cubren los puntos más importantes del subcontinente y finalizan con la instalación de la sucursal de Lima en 1875. Los Archivos Nacionales de Francia solo conservan los documentos relativos al funcionamiento de cuatro oficinas Havas-Reuters, Lima (1875-1887), Pernambuco (18751882), Buenos Aires (1881-1887 y 1896-1940) y Río de Janeiro (1902-1940). Por razones técnicas y económicas, ninguna sucursal es independiente de la red y su funcionamiento es imposible fuera de ella. El modus operandi de este conjunto puede centralizarse en los servicios que ofrecen las agencias de prensa en el continente sudamericano.

\section{Los servicios agencieros de la segunda mitad del siglo XIX para América del Sur}

Otro elemento pasado por alto por la historiografía agenciera radica en la sola referencia a los servicios que una agencia de noticias ofrece durante el siglo XX: servicios de prensa y orientados a ella. Es ignorar las principales actividades que realizaban las empresas telegráficas del siglo XIX: la transmisión de los llamados despachos «privados» y otros servicios de información de carácter comercial o financiero, que constituyeron en realidad los servicios clásicos de Havas y Reuters. El carácter específico de estos servicios hizo que la clientela distara mucho de ser la prensa sudamericana. En realidad, el servicio de información noticiosa o de orientación periodística es secundaria hasta la última década del siglo XIX.

Así, el servicio más importante de este periodo fue sin lugar a dudas el de despachos «privados». Básicamente se trata de un correo personal, como el postal, entre particulares, a través del telégrafo. Era un servicio sumamente raudo para la época, que sirvió generalmente a los comerciantes extranjeros establecidos en América del Sur.

Le siguió en importancia el servicio de informaciones, que podía ser dividido, por un lado, en el servicio comercial y financiero, y, por el otro, en el servicio político. Los despachos o telegramas comerciales y financieros 
fueron los más abundantes. Los primeros dieron cuenta de las materias primas extraídas del subcontinente, y los segundos, de los movimientos de capitales entre América del Sur y Europa. En resumidas cuentas, el flujo de información que venía de Europa era mucho más denso que el originado en Sudamérica. El servicio político, con el correr del tiempo, adquirió un carácter "periodístico», pues dio fe de los principales eventos que ocurren en los dos lados del Atlántico. Pero una tendencia fue perceptible desde este momento: las noticias sudamericanas que tendían a llamar la atención del público europeo fueron las catástrofes, los desastres, los asesinatos, los conflictos políticos y las bancarrotas comerciales.

El servicio político también fue útil a la comunidad de inmigrantes, que crearon sus propios periódicos en la región sudamericana. En el Perú, la inmigración - aunque mínima, si la comparamos con el resto de Sudamérica- formó las colonias italiana, inglesa y francesa. La mayor parte de europeos que llegó al Perú lo hizo en razón del boom guanero. Estos miles de inmigrantes se establecieron principalmente en Lima y en el litoral del Pacífico.

En Brasil, el servicio de «privados» debutó en 1874, y el de informaciones, en 1875. Ese mismo año, los «privados» se hicieron conocidos entre los países hispánicos. Elie Mercadier hizo debutar el servicio de informaciones en todas las sucursales sudamericanas simultáneamente en 1876, pero solamente fue exitoso en los países del sur (Argentina y Uruguay), cuyo crecimiento puede explicarse en gran medida gracias a su impresionante inmigración, lo cual les permitió reunir una cantidad consistente de suscriptores.

Un servicio «a la carta» conocido como el «aviso de vapores» registró la llegada de inmigrantes y mercancías a los puertos atlánticos de América del Sur, sobre todo a Pernambuco, Río de Janeiro, Montevideo y Buenos Aires. La información enviada por medio del telégrafo a Europa fue, gracias a un código especial utilizado por los agentes, el número de los recién llegados al subcontinente. Estos puertos recibían principalmente a los trasatlánticos ingleses. 


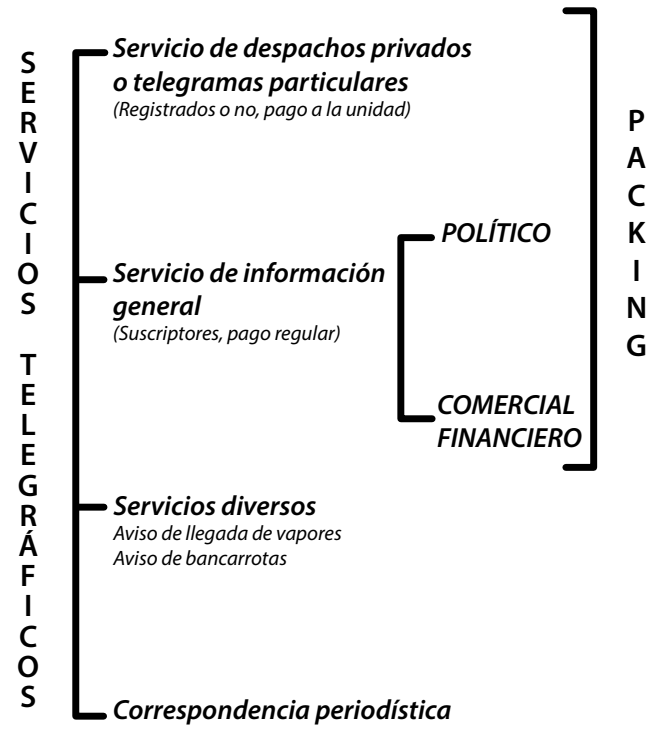

Un servicio altamente rentable fue el de «anuncios de bancarrota», que enumeraba las empresas, especialmente extranjeras, como los bancos o sus filiales y demás compañías, que se declaraban en bancarrota en Sudamérica. Esta información, que era inmediatamente transmitida a las empresas-madre con sede en Europa, constituyó una gran fuente de ingresos para Havas y Reuters.

Las evocaciones a este servicio se encuentran únicamente en los archivos correspondientes a la sucursal de Lima, lo cual no asegura que fuese un servicio privativo de la sucursal peruana:

Ce n'est pas à dire que vous devez nous signaler [toutes] les faillites. On ne devra en user [la clé] que dans les grandes circonstances et lorsque les services de renseignements seront bien organisés ${ }^{19}$.

Para la realización de un servicio informacional de este tipo, el personal de las sucursales poco tiene que ver con los primeros redactores o corresponsales de prensa «clásicos» que nos imaginamos hoy en día. A diferencia de lo que ocurre en América del Norte y Europa, donde los diarios establecen corresponsalías en el extranjero con reporteros deseosos de

19 «No tenemos necesidad de recordarle que nos debe informar sobre todas las bancarrotas. No usará la clave más que para las grandes ocasiones y cuando los servicios de información estén bien organizados». Archivos Nacionales, 5 AR 57 (5), f. 121. Nota sin fecha de Charles Emard a las sucursales de Lima y Valparaíso, c. 1876. 
cubrir los grandes eventos de la humanidad, el continente sudamericano es, al menos en un primer momento, el destino de «agentes» que no salen a buscar noticias, sino que se dedican a la compraventa de servicios de información. La información podía ser de diversos tipos, pero era, esencialmente, producida en Europa. Como los corresponsales o «stringers», los agentes podían ser reclutados localmente o en el extranjero sin tener ni siquiera una formación especializada. Ellos vigilaban, antes que todo, los intereses comerciales de sus empresa-madre, las agencias de información. En el caso que nos interesa, podían pertenecer a las primeras generaciones de inmigrantes, generalmente franceses o británicos. Algunos de ellos, claro está, fueron conocidos luego como grandes reporteros ${ }^{20}$, pero no desmintieron la regla general agenciera de este periodo, que mostró más a un personal comercial interesado en el rendimiento de la oficina que tenían a su cargo y, sobre todo, en la producción de ganancias. Entre los agentes más conocidos instalados en América del Sur, hallamos por supuesto a Walter F. Bradshaw, agente en Valparaíso durante cinco años y que a principios del siglo XX llegó a la cúpula directiva de la agencia británica. En todo caso, en este periodo, los agentes estudiados fueron todos de origen europeo y utilizaron el francés como lengua de comunicación.

\section{Havas-Lima}

La menos importante de las sucursales hispánicas del Pacífico, la oficina Havas-Reuters de Lima, formó parte de la más antigua ruta comercial interamericana, que cubrió las costas del Pacífico desde Acapulco hasta el Callao y las costas chilenas. Toda mercadería proveniente de Panamá o del puerto de Arica, desembocadura del Potosí, siguió esta ruta. Durante el siglo XIX, la capital del Perú fue el eje marítimo que unía Panamá al estrecho de Magallanes en el Atlántico sur. En este periodo, un cable submarino que partía del Callao unió Lima y Valparaíso.

El Perú contaba, además, con dos pequeñas líneas que unían su capital al Callao, su puerto, y a Chorrillos, su balneario más importante. Un grupo capitalista norteamericano, dirigido por Enrique Meiggs, autor de la comunicación entre Valparaíso y Santiago en Chile, emprendió el estudio, en 1869, de un recorrido «transandino», que, dados los recursos mineros de la zona, parecían augurar un gran futuro para el país.

20 Ya hemos mencionado a Elie Mercadier (1844-1916), quien realizó un viaje de prospección comercial en el subcontinente en 1875. Aunque la presencia de algunos periodistas corresponsales se hizo necesaria en ciertos lugares a principios del siglo siguiente, fue a la llegada de la Primera Guerra Mundial que la cobertura periodística se hizo obligatoria en el territorio sudamericano. 
Los servicios públicos estuvieron así en manos extranjeras: los ferrocarriles y el transporte urbano pertenecían a sociedades inglesas, mientras que otras compañías, igualmente foráneas, controlaban el telégrafo.

Luego del apogeo del guano durante el Gobierno del presidente Castilla, un conflicto con la Marina española hizo de la década de 1860 un periodo de disturbios políticos. El inicio de la década siguiente ofreció, por el contrario, una época un tanto más pacífica, lo que permitió una mejora en el nivel de vida:

Le Pérou a joui d'une profonde tranquillité pendant trois ans. La prospérité matérielle s'est considérablement accrue: mais les conditions de la vie s'y sont beaucoup modifiées, et la ville de Lima a fini par devenir la résidence la plus chère des deux Amériques ${ }^{21}$.

Situada en el numero 19 de la calle Jesús Nazareno ${ }^{22}$, la sucursal del centro de Lima existía por lo menos desde mediados de 1875. Los más antiguos documentos correspondientes a esta oficina datan de noviembre del mismo año ${ }^{23}$. Las cartas dirigidas desde París eran firmadas por la sociedad Havas-Laffite de 1875 a 1877. Enseguida, la firma de Charles-Louis Emard apareció de forma más frecuente. Las cartas de la sucursal de Havas de Londres para Lima cesaron en marzo de 1877.

Aparentemente, Havas-Lima fue la última sucursal fundada durante la ejecución de este primer plan de desarrollo agenciero. Su situación geográfica la mantuvo, sin embargo, alejada del resto de la red, puesto que Lima no tenía acceso directo al cable trasatlántico que unía América del Sur a Europa. Esta situación no la favoreció en nada.

El primero en dirigir la sucursal peruana fue Lucien Veber ${ }^{24}$ (18751877) ayudado por lo menos por otro empleado. Veber fue, aparentemente, enviado a Lima por Elie Mercadier para ocuparse de la sucursal en julio de 1875:

Il est regrettable que malgré ce que vous nous dites de l'absence complète d'instructions sur ces matières où vous avez, dites vous, été laissé lorsque M. Mercadier vous a envoyé de La Plata au Pérou, vous

21 «El Perú ha gozado de una profunda tranquilidad durante los últimos tres años. La prosperidad material se ha engrandecido y las condiciones de vida se han modificado sobremanera. La ciudad de Lima se ha convertido en la capital más cara de las dos Américas». A.M.A.E., Correspondencia Política, Perú, v. 34, D.P. Nro. 17, el Baron Gauldrée Boilleau, enviado extraordinario y ministro plenipotenciario al conde de Rémusat, ministro francés de asuntos extranjeros. Lima, 3 de agosto de 1871.

22 Archivos Nacionales, 5 AR 63.

23 Archivos Nacionales, 5 AR 57 (5), f. 1 Havas-Laffite à l'agent de Lima, Lucien Veber. París, 16 de noviembre de 1875.

24 El apellido Veber puede escribirse a la inglesa Weber. 
n'avez pas été plus pressant dans vos négociations et vos demandes en Europe ${ }^{25}$.

Luego, un representante de Havas, el miraflorino de origen inglés Norman Evans, fue el encargado de ponerse al frente de la sucursal de Lima.

En lo que concierne a la prensa, diarios como El Nacional, El Comercio, La Sociedad (órgano del clero peruano (El Heraldo de Lima (medio del general Echenique), La República, el diario oficial El Peruano y un diario italiano, La Patria, atrajeron los apetitos de las agencias.

El monto por abonarse al servicio político enviado a la sucursal de Lima era de 7000 francos mensuales. Uno de los primeros clientes de la prensa peruana fue el diario de las «clases iluminadas», El Nacional ${ }^{26}$. Poco tiempo después, el diario El Comercio se abonó también. Estos dos periódicos simpatizaban con la postura civilista de Manuel Pardo, presidente del Perú de 1872 a 1876. En noviembre de 1877, el servicio político se hizo cotidiano. $Y$ aunque por un breve periodo el Gobierno peruano se abonó a este servicio, les dirigentes de Havas desearon en todo momento aumentar el número de clientes receptores del servicio político.

El servicio comercial era enviado semanalmente vía Valparaíso, sucursal que lo recibía de Londres, vía La Plata. La Junta Comercial fue en todo caso el cliente más importante de este servicio enviado desde Havas-París. Su precio se elevaba a 3000 francos mensuales. Este servicio común a las dos sucursales del Pacífico fue lamentablemente de corta duración en Lima.

Casi inmediatamente, la agencia Havas tuvo intención de abonar a los Gobiernos sudamericanos a cambio de ciertos privilegios y conveniencias:

II y a tout avantage pour le Gouvernement péruvien, à profiter de l'immense publicité que nous donnons aux événements pour nous les signaler lui-même dans le sens qu'il juge le plus favorable à ses intérêts, et éviter ainsi qu'ils ne soient présentés par d'autres voies, d'une façon pouvant lui être préjudiciable. Non seulement le gouvernement pourrait nous signaler par télégraphe les événements importants, mais il pourrait aussi, par courrier, nous envoyer un résumé de la situation politique du pays, et ce résumé, serait communiqué par nous à tous les journaux d'Europe, sans indiquer la sources des nouvelles y contenues ${ }^{27}$.

25 Archivos Nacionales, 5 AR 57 (5), f. 35. Havas-Laffite à l'agent de Lima, Lucien Veber. París, 23 de enero de 1876. Para lo concerniente a Elie Mercadier, ver la segunda parte de este trabajo. 26 El propietario del diario era el doctor Manuel María del Valle, representante de las altas clases sociales limeñas y partidario de don Manuel Pardo, político civilista.

27 «El Gobierno peruano tiene mucho que ganar si sabe aprovechar la publicidad que daríamos a los eventos que nos indiquen, en el sentido de que le fuera más conveniente a sus intereses. Así evitaríamos una presentación de los mismos por otros medios, que le sería 
La agencia francesa ofrecía de esta manera una forma de publicidad en Europa a cambio de las primicias informativas, hoy llamadas «scoops», facilitadas por algún Gobierno.

En cuanto al servicio de despachos privados, este es anunciado por el diario El Comercio de Lima a partir de julio de $1875^{28}$ :
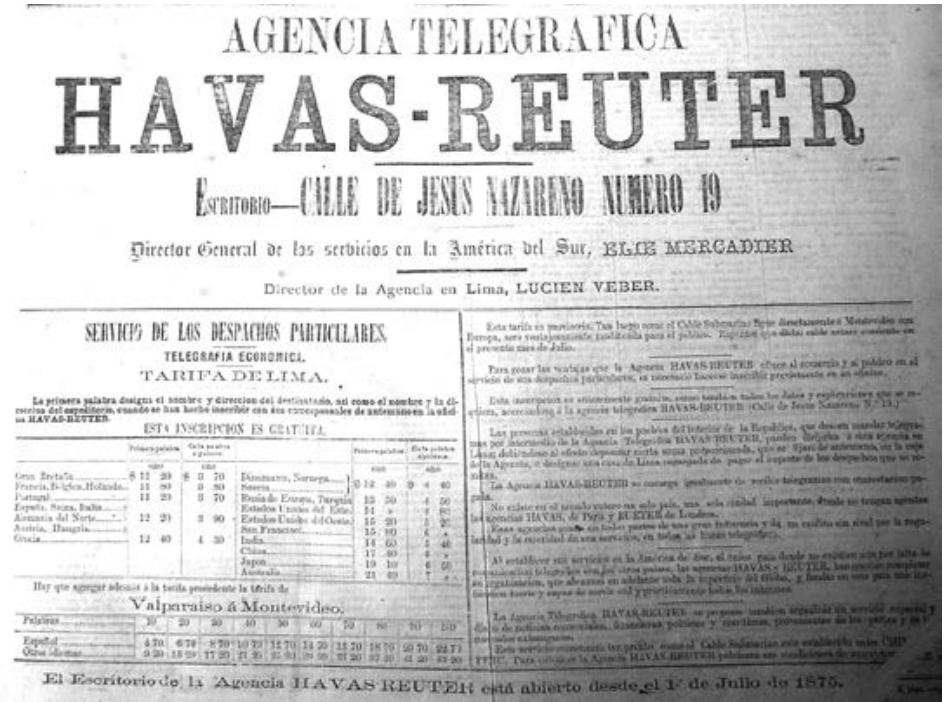

Fotografía de un anuncio Havas-Reuter(s) en el diario El Comercio

Lima enviaba y recibía los despachos particulares de los «enregistrés» de Lima y de las localidades importantes situadas más al sur del país en ese entonces, como Arica y la ciudad boliviana de Antofagasta. Para los lugares situados al norte, como la ciudad de Guayaquil, debido a la ausencia de un telégrafo o de un cable, la transmisión de los despachos se realizaba a través del correo convencional. Además, las dos sucursales del Pacífico compartieron las listas de clientes o registros:

Nous vous envoyons par le courrier d'aujourd'hui le double des listes d'enregistrement Pérou et Chili ainsi que celui des instructions qui vous [ont] déjà été expédiées par le courrier du 16 octobre ${ }^{29}$.

perjudicial. El Perú podría indicarnos por telégrafo los acontecimientos importantes y podría, además, por vía postal, enviarnos un resumen de la situación política del país. Este resumen sería transmitido por nosotros a todos los diarios de Europa, sin mencionar las fuentes de las noticias que enviaríamos». Archivos Nacionales, 5 AR 57 (5), ff. 246-247. Charles Emard al agente de Lima, Norman Evans. París, 15 de enero de 1879.

28 Fuente: El Comercio, edición de la tarde, nro. 12 418, 2 de julio de 1875. Agradecemos al profesor Juan Gargurevich por facilitarnos esta información.

29 « Le enviamos con el presente correo las listas de registros del Perú y Chile en doble ejemplar, así como las instrucciones que ya se le remitieron con la carta del 16 de octubre». 
La ruta era larga para este tipo de informaciones. Los «privados» con destino a Europa eran generalmente enviados de Lima a Valparaíso, de Valparaíso a Montevideo, y de Montevideo a Londres, que transmitía enseguida a París. Para realizar este envío, los gastos de la sucursal de Lima incluían los del trayecto Valparaíso-Montevideo y el de Lima-Valparaíso. Los directores de Havas eran muy precisos en este aspecto:

Veillez bien nous vous le rappelons de nouveau à ce que vos tarifs comprenant les prix en or de façon à que en outre du prix conventionnel du prix de la dépêche de Lima à Valparaiso, vous perceviez pour chaque mot au moins ce que Valparaiso et Montevideo ont à payer pour la retransmission en Europe ${ }^{30}$.

Puede ser que un despacho de Lima a Londres fuese enviado directamente de Lima a Valparaíso y de Valparaíso a Londres sin que el telegrama pasara por la sucursal de Montevideo. Dado este largo trayecto que un solo despacho debía seguir y el costo elevado de las transmisiones, el agente de esta sucursal estaba obligado a agrupar los despachos privados del día en un solo envío, en un solo «pack», y dirigirlo a Valparaíso. El agente Lucien Veber trabajaba de esta manera en conjunto con el agente de Chile, Walter F. Bradshaw, y decidían juntos el horario más conveniente para realizar estos envíos.

Si bien al principio de su funcionamiento la sucursal de Lima producía beneficios gracias a una buena actividad de su servicio de telegramas privados, la situación se transformó radicalmente hacia finales de la década de 1870. Cuatro fueron las razones principales de este declive.

En primer lugar, de todas las posesiones de Havas en la América hispánica, la sucursal de Lima fue la que sufrió más de su aislamiento geográfico. Havas-Lima afrontó de este modo las tarifas telegráficas más elevadas de todo el continente sudamericano y, por lo tanto, una gama de servicios extremadamente onerosos.

Una segunda dificultad provino de la imposibilidad de establecer de forma definitiva el servicio de informaciones. El servicio comercial, por ejemplo, funcionaba únicamente los dos primeros años, es decir, de 1875 a 1877. La sucursal sobrevivió solo por sus despachos privados, pero este servicio era realmente mínimo.

Archivos Nacionales, 5 AR 57 (5), f. 11. Havas-Laffite al agente de Lima, Lucien Veber. París, 23 de noviembre de 1875.

30 Archivos Nacionales, 5 AR 57 (5), f. 24. Havas-Laffite al agente de Lima, Lucien Veber. París, 23 de enero de 1876. 
En tercer lugar, la brevedad de la presencia de Lucien Veber como dirigente de esta sucursal fragilizó considerablemente todo desarrollo. De hecho, por razones de salud, Veber, quien hasta entonces dio muestras de una eficacia y de una probidad irreprochables y relativamente raras para la explotación sudamericana en general ${ }^{31}$, renunció a su puesto al cabo de dos años de servicio. La dirección de Havas lamentó esta decisión:

Nous tenons à vous exprimer le regret que nous cause votre détermination d'abandonner la Direction de notre agence au Pérou au moment où l'organisation du service de renseignements doit nous faire espérer le développement de nos affaires dans le pays ${ }^{32}$.

A pesar de todos los intentos de la dirección parisina por retener a su agente (incluso le propusieron un aumento de salario), Lucien Veber dejó definitivamente su puesto en abril de 1877. Antes de irse, Veber propuso dos candidatos para reemplazarlo: un empleado de la Junta Comercial (como ya lo hemos mencionado antes, uno de los clientes - por no decir el único- del servicio comercial de Havas), un tal Lemâle, y otro proveniente de The Pacific Steam Navigation Company de Liverpool ${ }^{33}$. Havas escogió al segundo, porque le pareció menos amenazador para los asuntos agencieros: Norman Evans, ciudadano británico.

Sin embargo, y luego de algunos meses en el puesto, Evans no demostró ser el agente ideal para una sucursal tan vulnerable como la de Lima. La oficina apenas si producía beneficios y se alejó cada vez más de los estándares de desarrollo que alcanzaban las demás sucursales sudamericanas. Para 1880, la sucursal fue excluida de las principales actividades que estas realizaban en forma conjunta. Havas-Lima fue prácticamente dejada de lado en las principales decisiones que se tomaban en París concernientes a las nuevas claves, las renovaciones de ciertos servicios y las palabras convencionales de Valparaíso, de La Plata y de Brasil: «Vous n'avez nul besoin des enregistrements de Bahia, Pernambuco, etc., ni même de ceux de Valparaiso» ${ }^{34}$. No obstante, como Norman Evans no reclamó nunca un salario importante, fue mantenido en su puesto de manera indefinida.

\footnotetext{
31 La mayor parte de las sucursales sudamericanas presentan en algún momento algún caso de malversación de fondos.

32 «Queremos expresarle nuestra decepción ante su decisión de abandonar la dirección de nuestra oficina en el Perú justo en el momento en que la organización del servicio de informaciones nos da esperanzas de ver desarrollarse nuestros negocios en ese país». Archivos Nacionales, 5 AR 57 (5), f. 158. Havas-Laffite à l'agent de Lima, Lucien Veber. París, 22 de marzo de 1877.

33 Esta compañía realiza un servicio de Liverpool a Montevideo y en el Pacífico.

34 «Usted no necesita utilizar los registros de Bahía, Pernambuco, etc., ni siquiera los de Valparaíso». Archivos Nacionales, 5 AR 57 (5), f. 288. Charles Emard al agente de Lima, Norman Evans. París, 5 de setiembre de 1880.
} 
La situación empeoró con la llegada de la Guerra del Pacífico (18791883), que firmó el acta fúnebre de esta sucursal. Por primera vez se hablaba de una posible clausura de la oficina limeña: «Nos affaires avec le Pérou sont devenues tellement restreintes depuis quelques mois que nous étudions en ce moment la question de [la] suppression de ce service, plus onéreux que productif ${ }^{35}$.

Felizmente, la inauguración del cable Panamá-Callao en 1882 salvó a la sucursal de Lima de una clausura inminente. La dirección de Havas en París quiso creer que finalmente la sucursal en el Perú iba a producir beneficios. Además, Evans aceptó dejar de percibir un salario y ser remunerado únicamente a comisión. Esta cifra aumentaría de acuerdo con la cantidad de despachos privados que lograra reunir y enviar.

Pero la guerra había aniquilado los intercambios comerciales entre el Perú y Europa.

\section{La Guerra con Chile (1879-1883)}

El gran acontecimiento de este periodo es entonces la Guerra del Salitre, que enfrentó al Perú junto con Bolivia a Chile. Es la primera guerra sudamericana «cubierta» por las agencias internacionales de información.

A pesar de que el acuerdo Joint Purse Agreement era válido hasta luego de 20 años, la agencia francesa pidió su revisión y su consiguiente cesación en mayo de 1876. Entonces, a partir de julio la zona sudamericana pasó a ser exclusividad de Havas. No obstante, la huella de las dos grandes agencias europeas quedó visible aún durante un buen tiempo en el desarrollo de la futura red de información en América Latina.

Las relaciones entre Havas y Reuters en ese momento se tornaron algo tensas y no solo por la disolución del acuerdo. Según Havas, además del aparente desinterés de Reuters en la zona sudamericana, una actuación más bien desleal de la agencia británica, en otras partes del mundo se acentuó este malestar.

En la segunda mitad del siglo XIX, la actualidad internacional que interesaba a Europa se caracterizó por un eurocentrismo sumamente marcado: "L'actualité européenne et coloniale passe avant» ${ }^{36}$ (Palmer, 1983, p. 112). Esta relativa indiferencia por todo lo que es considerado extranjero puede explicarse a través del contexto ideológico de la época,

35 «Nuestros negocios en el Perú se han vuelto tan difíciles que desde hace algunos meses estamos pensando en suprimir esta sucursal. Su existencia es más onerosa que productiva». Archivos Nacionales, 5 AR 57 (5), f. 289. Emard al agente de Lima, Norman Evans. París, 20 de setiembre de 1880 .

36 «La actualidad europea y colonial pasa primero». 
que colocó a la civilización europea como el modelo superior a imitar. Para el historiador René Girault, son cuatro los factores que determinaron un interés europeo por lo foráneo:

1. La posición geográfica

2. La frecuencia de los intercambios económicos y de personas

3. La desconfianza y el miedo hacia el otro

4. La importancia geopolítica o demográfica de este otro

Así, «l'opinion publique française ou allemande se souciait très peu des relations sur l'Amérique Latine ou l'Asie» (Girault, 2004, p. 75). Los acontecimientos sudamericanos susceptibles de provocar un interés de la parte del público europeo concernían, ya lo hemos dicho, lo que se conocieron después como las noticias sensacionales (Stone, 1921, p. 77).

Las catástrofes de origen natural (como los terremotos) o antrópico (como los incendios) y sobre todo la desaparición o el asesinato de personas famosas constituían la prioridad. En París, se tenía la idea de que la agencia se podía servir de los agentes ya instalados, cuando era necesario. Sin embargo, la realidad era otra:

Nos agents en Amérique [du] Sud ont instruction de nous télégraphier les nouvelles, quand elles sont réellement importantes, c'està-dire quand elles peuvent intéresser l'Europe. II est évident que l'assassinat de Manuel Pardo ${ }^{37}$ rentrait dans cette catégorie de faits. Nous sommes très étonnés de ne pas en avoir été avisés, et nous écrivons à qui de droit pour demander des explications. II a du y avoir quelque erreur ou quelque malentendu regrettable ${ }^{38}$.

Así se explica la agencia Havas ante su aliado Reuters cuando la primera pasó por alto la transmisión de una noticia a todas luces digna de llamar la atención entre los suscriptores europeos.

Los conflictos armados despertaban aún más la curiosidad periodística tanto en Europa como en Estados Unidos. Y a nivel de agencias, la guerra suscitó y reflejó una movilización mediática superior a aquella que producía cualquier otro evento:

37 Manuel Pardo (1834-1878), presidente del Perú (1872-1876).

38 «Nuestros agentes en América del Sur tienen instrucciones de telegrafiarnos las noticias, cuando estas son realmente importantes, es decir, cuando pueden interesar en Europa. Es evidente que el asesinato de Manuel Pardo entraba en esta categoría de hechos. Estamos muy sorprendidos de este silencio y escribimos a quien corresponda para pedir explicaciones. Debe haberse tratado de un error o de un malentendido lamentable». Archivos Nacionales, 5 AR 63 (4), f. 83. Henri Houssaye a la Reuter's Telegram Company. París, 20 de noviembre de 1878. 
Le phénomène de la guerre est souvent à l'origine des grandes périodes d'expansion des agences. Les guerres ont aussi encouragé les autres media à accroître leurs équipes à l'étranger, à développer la place accordée aux rubriques d'informations étrangères et à créer ainsi une demande du public pour celles- $\mathrm{ci}^{39}$ (Boyd-Barrett y Palmer, 1981, p. 250).

Desde la instalación de las sucursales sudamericanas, los eventos que ocurrían en el subcontinente eran cada vez menos ignorados por la parte del mundo occidental. Los agentes comenzaron a efectuar, además de los otros servicios, una corresponsalía periodística ${ }^{40}$. Luego de las guerras de independencia de inicios del siglo XIX, fueron tres los enfrentamientos que sucedieron en América del Sur a partir de 1860.

El primer conflicto enfrentó a Ecuador, Chile y el Perú contra España en 1866. Las noticias sobre esta contienda llegaron a Europa a través de los vapores que transportaban el correo. El segundo litigio fue la Guerra de la Triple Alianza, que opuso a Paraguay contra el bloque compuesto por Argentina, Brasil y Uruguay de 1864 a 1870. Este último conflicto tuvo mayor acogida en Europa, quizá por los intereses británicos apostados en la lucha. Charles A. Jones lo explica de la siguiente manera:

L'Amérique du Sud était problématique puisqu'elle présente un faible intérêt politique pour le lecteur britannique moyen malgré l'intérêt financier significatif qu'elle représente pour une minorité importante. Quoi qu'il en soit, elle doit être couverte ${ }^{41}$.

39 «El fenómeno de la guerra a menudo se encuentra a la raíz de los grandes momentos de expansión agenciera. La guerra también favorece el desarrollo de otros medios de comunicación por medio del aumento de su personal en el extranjero, de la importancia que se da a esta en la página de internacionales y de la consiguiente creación de una importante curiosidad en el público por ella».

40 «Ruffier and Bradshaw also began to return reports on South American events to Europe» (Desmond, 1978, p. 250).

41 Traducción libre de un fragmento del siguiente párrafo: «These, after all, were the pioneering days of foreign correspondents: The Times maintained no full-time, professional correspondent in South America until some twenty years later. Correspondents were first appointed to select European and North American centres, and only later to more distant points, where they presided nervously over vast tracts of the less developed world. Both the distribution of foreign correspondents and their copy were bound to be limited by the prevailing trends and foci of British foreign policy, and in this respect, South America presented a problem, since it was of little political interest to the average British reader, yet of considerable financial importance to a significant minority. Plainly, it had to be covered. Yet, equally plainly, it did not merit the depth of news coverage accorded to Britain's closer friends and enemies. Consequently, South American news was generally confined to the City pages of the dailies, and to the specialist financial press. This news, in turn, was derived from a hotch-potch of sources. Each City editor had a circle of "reliable" and "authoritative" sources, who might be relied upon from time to time for scraps from the London Boardrooms of companies operating in South America, or snippets from letters and telegrams received form managers and agents in foreign centres. Space was filled by printing Directors' Reports, and the minutes of Annual General Meetings. Then, there were the "special correspondents", who sent back series of letters from a particular centre, or relating to a particular branch of commerce. Later, 
Sin embargo, ninguno de estos dos enfrentamientos recibió el mismo grado de atención por parte de la prensa europea como ocurrió con la Guerra del Pacífico.

La guerra con Chile es la primera conflagración verdaderamente mediática en América del Sur. En efecto, fue la primera en ser fotografiada ${ }^{42}$ y, además, representó una ocasión sin precedentes que puso a prueba el ejercicio y el funcionamiento de las sucursales agencieras, sobre todo en cuanto a la transmisión de informaciones «políticas» sudamericanas a Europa.

A fines de 1878, en el momento en que estalló la crisis chileno-argentina por el establecimiento de las fronteras en la Patagonia, un corresponsal de un diario norteamericano se desplazó a Chile ${ }^{43}$. La Guerra del Pacífico fue entonces «cubierta» por algunos periodistas de los grandes diarios, pero también por las agencias.

La producción y la difusión de la información por parte de la agencia Havas durante el conflicto pueden medirse a partir de algunas de sus publicaciones. Su servicio extranjero distribuyó las Hojas Havas a toda la prensa parisina, a horas precisas, para que extrajeran los despachos y las noticias que le convenían. Pero es la Correspondance Générale Havas la que dio las principales noticias recibidas en las últimas 24 horas $^{44}$. Havas también publicó algunas traducciones como II traductione de forma puntual. Solo la Correspondance Havas y una que otra feuille en alemán podían ser consultadas en la Biblioteca Nacional de Francia en forma de microfilms ${ }^{45}$.

Nuestro punto de apoyo será entonces la Correspondance Générale Havas publicada por la agencia francesa. Ella nos ayudará a abordar las diversas tentativas para lograr una correspondencia periodística sobre este evento. En general, los despachos que tratan de América del Sur aparecen al final de la sección «Dépêches télégraphiques». No obstante, otras informaciones, más importantes, en relación con Sudamérica, podían ser

these were reinforced or replaced by full-time, professional correspondents. But the largest source of news-in-bulk was reprints from the English-language newspapers published in South America for the benefit of resident of English resident communities, and which, in turn, included a good deal of material translated from the local Spanish-language press» (Jones, 1979, pp. 2-3).

42 Agradecemos a Marie-Danielle Demelas por esta información.

43 A.M.A.E., Correspondencia Política, Chile, v. 21, Dirección Política, Nro. 63, f. 135, M. el Baron d'Avril, ministro de France en Chili a M. Waddington, ministro de Asuntos Extranjeros, Santiago de Chile, 19 de noviembre de 1878 . No se mencionan, sin embargo, ni el nombre de dicho periodista ni del diario estadounidenses.

44 Archivos Nacionales, 5 AR 68 (4), f. 28 Ernest Barbier au general manager de la Reuter's Telegram Company. París, 14 de febrero de 1917.

45 Correspondance Havas, BNF, codigo MICR D-1387 (support microformé). Quelques Feuilles Havas datant des années 1930 existent sous forme imprimée. 
desplazadas a la sección «Nouvelles de l'étranger» o alguna otra rubrica según el contenido.

La Correspondance Générale presenta, de forma manuscrita, el aspecto de un «journal pour journaux», donde el comentario es menos importante que la enunciación de los hechos y que la traducción de los hechos que se cuentan en el extranjero (Frederix, 1959, pp. 45-46). De esta forma abordó Havas la Guerra del Pacífico.

Cuando la conflagración estalló, los diarios europeos no carecían de noticias con las cuales llenar sus páginas ${ }^{46}$. Pero rápidamente se hizo evidente que los intereses extranjeros eran importantes:

Cette dernière république [le Chili] rêve depuis longtemps d'arracher à la Bolivie les dépôts de guano et les mines d'argent de Cobija, Mejillones et Caracoles, et je ne doute pas qu'elle ne mette de côté tout scrupule pour satisfaire cette ambition. Je crois cependant de mon devoir de faire le plus possible pour empêcher une éventualité dont le premier effet serait de paralyser pour longtemps si non de ruiner les Compagnies minières de Caracoles dans lesquelles sont intéressés presque tous les français résidant au Chilii ${ }^{47}$.

Asimismo, las compañías chilenas que explotaban el salitre recibían fondos de las sociedades británicas como la de Anthony et Herbert Gibbs, y d'Edwards et Compagnie. El capital invertido por las compañías mineras chilenas fue de cerca de un millón de libras esterlinas (Graham-Yooll, 1985, p. 209). De allí el apoyo directo a Chile. Los franceses tendían a apoyar a Bolivia y al Perú. La situación se envenenó y alcanzó un grado de no retorno al firmarse el tratado secreto entre estos dos últimos países:

Il y a un mois environ, des bruits alarmants se produisaient avec une certaine persistance au sujet de la Bolivie. On affirmait qu'un traité d'alliance offensive et défensive venait d'être signé entre cette nation et le Pérou, que le but de cette union serait de déclarer prochainement la guerre au pays que j'habite. Ce bruit ne manquait pas de vraisemblance. Le Cabinet de Santiago a en effet donné à celui de La Paz, surtout dans la question des limites des deux états, de nombreux sujets de mécontentement. D'autre part, la guerre contre le Chili serait fort populaire au Pérou, ainsi que j'ai pu m'en assurer pendant mon séjour à Lima ; il est peu probable que cette république, en

\footnotetext{
46 En la misma época, la reina Victoria visitaba Italia e Inglaterra, tenía enfrentamientos finales con Afganistán y continuaba en África la guerra contra los zulúes. Se podía ignorar un conflicto aparentemente menor en América del Sur o minimizar su lugar en las noticias internacionales transmitidas por los periódicos.

47 A.M.A.E., Correspondance Politique, Chili, v. 19, Direction Politique, nro. 4, f. 170, le Marquis de Monclar, ministre de la France au Chili au comte de Rémusat, ministre des Affaires Étrangères. Santiago de Chile, 26 de julio de 1872.
} 
ce moment bien armée et en possession de la plus belle marine de guerre du Pacifique, attende, pour brusquer les événements, s'il entre réellement dans[les] projets d'en venir aux mains, que le Chili ait reçu de l'Europe les vaisseaux et les armements qu'il a commandés en Angleterre et en Belgique ${ }^{48}$.

Una vez que el Perú entró en la contienda para apoyar a su socio secreto, la Marina chilena cortó inmediatamente los cables submarinos tanto de la costa peruana como boliviana. Según el historiador finlandés Jorma Ahvenainen, se trató de la primera vez que unos beligerantes cortaban de forma voluntaria los cables telegráficos (Ahvenainen, 2004, p. 108). Sin embargo, el Times de Londres fue el primero en informar los inicios de la guerra. En realidad, el sábado 22 de marzo de 1879 publicó las primeras noticias concernientes a los inicios de la guerra, es decir, el conflicto diplomático-comercial. El sábado 22 de marzo de 1879, se publicó en sus páginas, con cuatro días de retraso, las primeras noticias que el diario inglés recibía vía Lisboa (Graham-Yooll, 1985, p. 210).

El 27 y el 29 de marzo continuó siendo el diario londinense que publicaba una pequeña noticia provista por el agente del Lloyd's ${ }^{49}$. De igual manera, divulgó un informe mucho más extenso sobre los preparativos de la guerra. Este periódico no contaba con un corresponsal en la zona de conflicto y obtuvo estas informaciones a partir de una noticia aparecida en un periódico de la región, en este caso preciso, del Panama Star and Herald. El corresponsal de este diario escribía desde Lima (Graham-Yooll, 1985, p. 210), en el núcleo de la disputa ${ }^{50}$.

La Correspondance Havas publicó un telegrama, proveniente de Roma, en mayo. Debido al punto de vista adoptado y por el lugar otorgado a esta información en la sección «Dépêches télégraphiques» (a la vertical y al margen), podemos darnos cuenta de que lo que interesa a los suscriptores es la presencia de los intereses extranjeros en el conflicto:

48 A.M.A.E., Correspondance Politique, Chili, v. 19, Direction Politique, nro. 4, ff. 162-163, le Marquis de Monclar, ministre de la France au Chili au comte de Rémusat, ministre des Affaires Étrangères. Santiago du Chile, 26 de julio de 1872.

49 «La façon dont les nouvelles arrivaient en Angleterre était la suivante: the standard pattern of communication during the last quarter of the nineteenth century remained one of "hot news" received by telegram, and printed with comment based on past experience, to be confirmed and amplified some three weeks later, when the mail boat reached England» (Jones, 1979, p. 2).

50 Eleazar Díaz Rangel agrega que La Estrella de Panamá de Colón recibe información de los periódicos peruanos transportados por vapores estadounidenses desde el Callao. Como regla general, los diarios de Estados Unidos dependían de la vía marítima para recibir noticias sobre esta guerra (Díaz Rangel, 1991, pp. 78-79). 
A la chambre des députés, $M$. Depritis a déclaré qu'il avait adressé aux agents diplomatiques et consulaires de gouvernement au Pérou, au Chili et dans la Bolivie, des instructions ayant pour but de maintenir la plus stricte neutralité parmi les résidents italiens et de recommander aux belligérants de résoudre leurs différends par l'arbitrage.

Enseguida, los administradores de la agencia parisina pidieron a sus agentes en el Perú y Chile que «cubrieran» este enfrentamiento naciente:

II nous serait utile de recevoir de vous, par lettre, des nouvelles politiques du Pérou non encore publiées par les journaux qu'emporte la malle. Vous devez profiter de votre situation comme représentant de I'Agence Havas pour avoir des relations suivies avec les divers ministres du Pérou et obtenir par eux de renseignements intéressants, en leur faisant comprendre que ces nouvelles seront publiées par nous en Europe dans un sens favorable au Gouvernement Péruvien ${ }^{51}$.

Gracias a Reuters, Havas pudo igualmente obtener noticias provenientes de Lisboa: «Veuillez avoir l'obligeance de nous réexpédier les télégrammes que vous recevez, via Lisbonne, sur les événements de la guerre que se font entre elles les républiques du Pacifique» ${ }^{52}$. Así, Havas-París recibía, vía Londres, telegramas de Lisboa provenientes de Pernambuco, pero también de Estados Unidos: «Nous vous remercions de l'ordre donné de nous réexpédier les nouvelles Pérou-Chili qu'elles viennent soit par Lisbonne, soit par l'Amérique du Nord $»^{53}$. «Par ailleurs, en plus des dépêches que l'agence Reuters reçoit par la voie Lisbonne, il lui arrive aussi d'en recevoir de Rio de Janeiro directement».

Pero, como lo evidencian las indicaciones dadas a los agentes sudamericanos, estos no tenían costumbre de transmitir una información de este tipo y no parecían estar a la altura de la situación ${ }^{54}$ :

Le reproche que vous nous adressez au sujet du mauvais service de nos agents Amérique Sud relativement aux nouvelles de cette guerre s'est trouvé justifié par une circonstance toute spéciale. La clé employée par notre agent à Valparaiso pour nous signaler la déclaration de

\footnotetext{
51 Archivos Nacionales, 5 AR 57 (5) f. 262. Charles Emard à Norman Evans, I'agent de Lima. París, 16 de mayo de 1879.

52 Archivos Nacionales, 5 AR 63 (4) f. 192. Edouard Lebey à la Reuter's Telegram Company. París, 20 de mayo de 1879.

53 Archivos Nacionales, 5 AR 63 (4) f. 195. Charles Emard à la Reuter's Telegram Company. París, 24 de mayo de 1879.

54 Reuters parece haber hallado similares dificultades durante la guerra de Crimea: «After the landing of Anglo-French forces, Reuter[s] did not claim to have his own reporters at the front. He had to depend upon his agents at Berlin, Vienna, Constantinople, and in the Balkans, and also on the Russian side at St Peterbourg and Odessa. These agents provided background news about military and diplomatic developments, not battlefield reports» (Read, 1999, pp. 18-19).
} 
la guerre n'est arrivée que trois jours après la dépêche qui nous signalait les mots de cette clé. Ce qui a fait que nous avons été devancés sans quoi nous [ne] l'aurions pas été ${ }^{55}$.

Havas recurrió igualmente a su socia norteamericana gracias a la intercesión de Reuters:

Nous croyons qu'il convient d'écrire à l'Associated Press de New York de vous télégraphier toutes les nouvelles qui lui sont adressées de Panama sur cette guerre, nouvelles qui porteront naturellement le cachet péruvien tandis que celles qui viennent par Lisbonne ont plus particulièrement la marque [?] chilienne puisqu'elles ont Valparaiso pour origine ${ }^{56}$.

Por ello, la indicación geográfica no indica únicamente el origen del telegrama, sino también la posible orientación de las fuentes empleadas. Los países extranjeros al conflicto parecían tomar partido y alejarse de la imparcialidad. De esta forma, al rendirse la ciudad de Lima, el Ejército chileno sacó a la luz las acciones poco gloriosas del personal diplomático peruano en Panamá, que se preocupó de crear en el extranjero una opinión favorable a las razones por las que el Perú estaba en guerra:

Il n'y a pas, à Panama, un seul individu qui ne connaisse la justice de notre cause, car je ne me suis pas borné à publier, dans les journaux de la localité, les manifestes de notre chancellerie et plusieurs articles en faveur du Pérou, mais encore je n'ai pas cessé de faire la propagande la plus active, sous toutes les formes ${ }^{57}$.

Al indicar el origen de los despachos telegráficos, los administradores de la agencia francesa deseaban mostrar su neutralidad y la extensión de su red de información:

Nous vous serons donc obligés de toujours indiquer la voie par la queIle sont venues les nouvelles: Panama, New York ou Lisbonne, et de donner des instructions bien précises de soigner ces expéditions ${ }^{58}$.

Desde el inicio de la guerra, los soldados chilenos acumulaban los éxitos. Las primeras informaciones correspondientes al estado ruinoso en el que quedó Bolivia aparecieron en el Times, que las tomó de El Heraldo

55 Archivos Nacionales, 5 AR 63 (4) f. 195. Charles Emard à la Reuter's Telegram Company. París, 24 de mayo de 1879.

56 Archivos Nacionales, 5 AR 63 (4), f. 195-196. Charles Emard à la Reuter's Telegram Company. París, 24 de mayo de 1879.

57 A.M.A.E., Correspondance Politique, Chili, v.23, f.113, Luis E. Márquez, consul du Pérou à Panama au ministre péruvien des affaires étrangères, le 29 juin 1879 Bulletin de la Guerre du Pacifique, nros. 51 et 52, du 6 avril 1881, Annexe à la dépêche politique, nro. 202. Enfatizamos. 58 Archivos Nacionales, 5 AR 63 (4), f. 196. Charles Emard à la Reuter's Telegram Company. París, 24 de mayo de 1879. 
de Cochabamba ${ }^{59}$ (Graham-Yooll, 1985, p. 211). Cuando el agente de Havas en Lima, Norman Evans ${ }^{60}$, partió al frente para defender su patria de adopción y no los intereses agencieros, a la dirección solo le restó contar con su sucursal de Chile: «Notre agent de Valparaiso a instruction de nous envoyer les nouvelles importantes, et nous espérons qu'il s'occupera [?] de son service d'une façon satisfaisante ${ }^{61}$.

Para dar cuenta de los eventos que se sucedían, Havas no deseaba detenerse en los detalles, sino en los «grandes» momentos de la guerra, aquellos que suponían una atención permanente por parte del público europeo: «ll [l'agent] doit naturellement se borner aux faits très importants, et négliger les petites nouvelles sans signification pour l'Europe» ${ }^{62}$.

A pesar de estas disposiciones, Havas no recibió ninguna noticia correspondiente a la batalla de lquique. No obstante, gracias al servicio de lectura y «desplumaje» de los diarios londinenses, la agencia francesa publicó, en primera página de su Correspondance, el domingo 1 de junio de 1879, las noticias concernientes a esta batalla. Bajo el título «Amérique Méridionale», se narró cómo las tropas y las unidades navales chilenas enfrentaron a una fuerza combinada peruano-boliviana entre lquique $y$ Tacna, del 21 al 23 de mayo:

Les journaux anglais publient la dépêche officielle suivante, qui leur a été communiquée par le représentant du Chili à Londres: Un combat a été livré à lquique, entre les cuirassés Huascar et Independencia d'un côté et les navires chiliens Esmeralda et Covadonga de l'autre. Le Covadonga a coulé l'Independencia, et la Esmeralda ayant été désemparée, le capitaine Thompson, qui la commandait, a fait mettre le feu aux poudres et l'a fait sauter.

Pero como la agencia Reuters le reprochó a Havas el hecho de recibir una información de origen diplomático en lugar de un despacho de agencia, la dirección de Havas aseguró:

Nous regrettons comme vous de n'avoir pas été avisés télégraphiquement par nos agents du combat naval engagé entre les marins chiliens et le cuirassé péruvien. Leurs instructions sont cependant bien formelles ${ }^{63}$.

59 Es un diario boliviano.

60 Agradecemos al señor Harry Evans, bisnieto de Norman, por habernos comunicado esta información.

61 Archivos Nacionales, 5 AR 63 (4), f. 200. Havas Laffite a la Reuter's Telegram Company, París, 27 de mayo de 1879.

62 Archivos Nacionales, 5 AR 63 (4), f. 200. Havas Laffite a la Reuter's Telegram Company. París, 27 de mayo de 1879.

63 «Como ustedes, nosotros también lamentamos el hecho de no ser advertidos telegráficamente por nuestros agentes sobre el combate naval entre los marinos chilenos y el buque 
No obstante, las fuentes diplomáticas británicas parecían ser eficaces, ya que Reuters mantuvo relaciones estrechas con el Ministerio de Relaciones Exteriores.

Desde 1857, en efecto, la agencia británica gozaba del privilegio de obtener en primicia una copia de los telegramas recibidos por el Foreign Office. Reuters «est informé en premier des communications officielles du gouvernement» (Boyd-Barret y Palmer, 1981, p. 96).

Ante el silencio de sus dos agentes de la costa del Pacífico, los administradores de París, al ver que la guerra se prolongaba, consideraron que había llegado el momento de recurrir al personal diplomático sudamericano interesado, para no estar en desventaja ante los diarios:

De notre côté, nous nous sommes mis en communication avec les légations du Chili et du Pérou, afin d'avoir plusieurs sources de renseignements. Nous supposons que vous en aurez fait autant, d'autant plus que les légations [sud-américaines] de Londres seront plus tôt informées que celles de Paris ${ }^{64}$.

Por ello, gracias a los datos proporcionados por el cónsul chileno en Londres, las agencias lograron obtener la primicia, 15 días antes que los periódicos británicos, de la pérdida del acorazado peruano Independencia. Esta es una noticia que el Times publicó solamente el 17 de junio. Además, este diario desmintió la versión según la cual el Esmeralda fue hundido por su propia tripulación y consignó que fue hundido por el acorazado peruano Huáscar. De todos modos, Chile era el vencedor en esa batalla.

Pero en su Correspondance, Havas publicaba generalmente telegramas de origen europeo, desde, evidentemente, este punto de vista. Así, el 13 de junio, un despacho telegráfico de Berlín anunció que:

La Gazette de l'Allemagne du Nord annonce que la corvette cuirassée La Hansa a reçu l'ordre de se rendre à Valparaiso pour protéger les intérêts des nationaux allemands dans les eaux du Chili et du Pérou. La corvette allemande arrivera probablement à destination dans le courant du mois de juillet.

Mucho después de ocurridos los hechos, Havas continuaba difundiendo los detalles de la batalla de lquique según los telegramas que le llegaban de Nueva York. En un despacho sorprendentemente extenso de tres párrafos, que ocupa tres cuartas partes de una columna de la tercera hoja,

peruano. Sus instrucciones son, sin embargo, bien claras». Archivos Nacionales, 5 AR 63 (4), f. 202. Havas-Laffite a la Reuter's Telegram Company. París, 1 de junio de 1879.

64 Archivos Nacionales, 5 AR 63 (4), f. 202. Havas-Laffite a la Reuter's Telegram Company, París, 1 de junio de 1879. 
del 16 de junio de 1879, es decir, 26 días después de iniciado el enfrentamiento, la agencia detalla:

Des nouvelles de Lima en date du 27 mai (voie Panama) donnent des détails sur le dernier combat naval devant lquique. Le vaisseau cuirassé péruvien Huascar ayant sommé la corvette en bois chilienne Esmeralda de se rendre, celle-ci répondit par une bordée. Alors le Huascar éperonna la Esmeralda qui coula bas immédiatement avec son équipage se composant de cent cinquante hommes dont 40 seulement ont été sauvés.

La voluntad de presentar igualmente la situacion politica interna de los países beligerantes quedó establecida con la información transmitida por el telegrama del 18 de junio de 1879, proveniente de:

Rio de Janeiro, 1er juin (Par dépêche de Lisbonne). Les avis de Valparaiso portant la date du 29 mai, annoncent que les Chiliens revendiquent pour eux la victoire, dans le combat naval d'lquique. [...] Les dernières nouvelles de Lima, annoncent que le congrès péruvien a adopté un projet de loi annulant tous les transferts de propriété effectués au profit des sujets chiliens, depuis le 14 février.

La divulgación de los preparativos de las siguientes escaramuzas es posible gracias a vías indirectas y no agencieras de transmisión:

New York, 3 juillet. Les avis de Panama du 24 juin constatent qu'un navire péruvien chargé d'armes avait quitté Panama malgré les protestations du consul chilien et la défense des autorités de Colombie. Le journal Star and Herald de Panama publie des nouvelles de Lima du 11 juin. Le vapeur allemand Luxor arrêté par le gouvernement péruvien à Callao, avait été relâché par suite de la médiation du ministre anglais.

Solamente dos rarísimos telegramas parecen provenir directamente de las sucursales sudamericanas y, especialmente, del agente Havas de Valparaíso, Walter F. Bradshaw ${ }^{65}$ :

Paris, 22 juillet 1879. Valparaiso, 29 juin (voie Lisbonne). La flotte chilienne continue le blocus d'Iquique. Le Huascar, reste au Callao pour réparer des avaries. Les armées, réunies du Pérou et de la Bolivie dont on évalue l'effectif à 20.000 hommes, attendent des armes et des munitions. L'armée chilienne est évaluée à 12.000 hommes. Les journaux de Valparaiso reprochent au gouvernement la lenteur des opérations.

65 Aparentemente, el único agente enviado por la agencia Reuters en 1875, cuando la invasión agenciera se hizo por partida doble de Havas y de Reuters, es Walter F. Bradshaw, quien permaneció en su puesto hasta inicios de la década siguiente Al iniciarse el siglo XX, Bradshaw fue secretario general de Reuters. 
El domingo 27 de setiembre de 1879, la Correspondance Havas propaló el bombardeo de la Marina peruana contra Chile. Este telegrama parece ser uno de los últimos enviados por la sucursal de Chile:

Valparaiso, 11 août. La nouvelle du bombardement d'Antofagasta, le 28 août par le Huascar est confirmée. La canonnière chilienne Abtao a été gravement endommagée. Elle a eu plusieurs tués ou blessés.La canonnière Magellanes a peu souffert ${ }^{66}$.

Siempre con un retraso de casi un mes, las noticias parecían ser extraídas del correo administrativo (y no telegráfico) que el agente enviaba a la sede de París.

Al mes siguiente, la agencia francesa publicaba las noticias sobre las primeras consecuencias de los eventos en América del Sur:

Paris, 1er août 1879. Les navires cuirassés. On lit dans le Berliner Tagblatt du 30 juillet "Il paraît résulter d'un ordre donné par l'amirauté de construire quatre corvettes plates à deux canonnières blindées qu'on a renoncé à la construction de navires plus grands tels que de frégates cuirassées, et que cette résolution a été prise en conséquence des expériences faites pendant la guerre russo-turque et de celle qui a lieu en ce moment dans l'Amérique du Sud entre le Chili, la Bolivie et le Pérou.

Así como el Times de Londres publicaba las noticias enviadas por los agentes del Lloyd's, la Correspondance Havas del 19 de agosto de 1879 difundió un despacho telegráfico muy ilustrativo de la eficacia de esta red de informadores de seguros marítimos. La noticia provenía de Londres: «Une dépêche du Lloyd's donnant des nouvelles de Panama, sans indication de date, annonce que le port d'lquique est ouvert et le blocus terminé».

Con el retraso habitual propio del correo postal, una comunicacion del agente de Valparaíso apareció en la Correspondance del 27 de agosto de 1879:

Valparaiso, 31 juillet. Des avis de Tupiza (Bolivie) en date du 28 juillet, annoncent que le navire de guerre chilien Chacabuco a tenté sans succès de s'emparer de la ville de Huanillos. 2.500 boliviens sont arrivés à Pisagua, venant de Tacna.

66 «Valparaíso, 11 de agosto. La noticia del bombardeo de Antofagasta, el 28 de agosto, por parte del Huáscar ha sido confirmada. La cañonera chilena denominada Abtao está sumamente dañada y un saldo de numerosos muertos o heridos. La cañonera Magallanes ha sufrido, en cambio, menos». 
Estas informaciones directas eran siempre muy raras $y$, generalmente, los telegramas que aparecían en la Correspondance Havas tenían los orígenes más diversos:

New York, 4 septembre. Les journaux publient un télégramme de Panama, 26 août, annonçant que le gouvernement péruvien a publié à Lima une dépêche annonçant que le cuirassé péruvien le Huascar a attaqué de nouveau les ports chiliens. L'Union a été envoyée dans le sud afin d'arrêter les vapeurs envoyés du Chili avec des munitions de guerre. Le gouvernement péruvien a télégraphié à MM. Althaus et Aranibar, ses délégués [des] finances en Europe, que leur mission était terminée.

Cuando la Marina chilena obtuvo un triunfo decisivo en el cabo de Angamos en octubre de 1879, Havas publicó la información al día siguiente gracias a los telegramas de los «Seguros marítimos» transmitidos por su aliada británica:

Londres, 9 octobre. Un télégramme du Lloyd annonce qu'à la suite d'un combat entre les flottes du Chili et du Pérou, le cuirassé Huascar a été capturé par les chiliens. Le combat a eu lieu près de la baie de Mejillones sur la côte bolivienne. La nouvelle de la prise du Huascar reçue d'abord par le correspondant à Londres de la banque Edwards de Valparaiso a été reçue également par une autre maison de banque de Londres ayant des relations commerciales avec le Chili67.

Una vez terminada la campaña naval, con Chile asegurándose el control de las vías de comunicación marítima, la guerra continuó en tierra. El 2 de noviembre, Havas ofreció detalles de la toma de Pisagua (al norte de Iquique) por los chilenos:

Paris, 24 novembre 1879. New York, 24 novembre. Une dépêche de Panama, 15 novembre, donne des détails sur la prise de Pisagua. La ville a été enlevée par 12.000 chiliens qui ont débarqué sous le couvert des canons de la flotte chilienne. La lutté a été assez vive. Il y a eu un grand nombre de morts des deux côtés. [...] Les deux armées réunies comptant en tout 9.000 hommes attendent les chiliens une bataille est imminente. Les troupes alliées d'Arica et de Tacna, marchent sur les derrières de l'armée chilienne. L'état de siège est proclamé à

67 Londres, 9 de octubre. Un telegrama de Lloyd anunció que, luego de una batalla entre las flotas de Chile y el Perú, el buque de guerra Huáscar fue capturado por los chilenos. La pelea tuvo lugar cerca de la bahía de Mejillones, en la costa boliviana. La noticia de la captura del Huáscar que recibió el corresponsal del Edwards Bank de Valparaíso en Londres también fue recibida por otra entidad bancaria de Londres, que mantiene relaciones comerciales con Chile. 
Lima. Le général La Puerta a formé un nouveau cabinet composé exclusivement d'amis personnels.

La siguiente «batalla inminente» ocurre en Tarapacá, donde las fuerzas aliadas fueron destruidas. En enero del año siguiente fue testigo del caos que reinaba al interior del Gobierno peruano: «Paris, 24 janvier 1880, Washington, 4 janvier. Le ministre des États-Unis au Pérou a demandé à son gouvernement des instructions relativement à la reconnaissance du général Piérola comme dictateur du Pérou».

Es únicamente el 11 de febrero de 1880 que las hojas matutinas de las Traductions Havas dieron cuenta de las insurrecciones ocurridas en las calles de la capital peruana. Bajo la forma de un artículo impresionantemente extenso de una columna entera, las informaciones transmitidas con el título «Pérou: La révolution de Lima» divulgaron los actos incendiarios de la noche del 18 de diciembre del año anterior.

En marzo, y siempre en la sección de traducciones de las hojas matutinas de la agencia Havas, del 10 exactamente, podemos leer un artículo más sucinto que enumera los últimos hechos de la confrontación:

Pérou: La guerre du Pacifique. Une dépêche de Buenos Aires, en date du 23 janvier, annonce que l'alliance entre le Pérou et la Bolivie a été rompue. On mande, de Valparaiso, à la date du 27 janvier, des obus ont fait explosion dans l'arsenal de cette ville. Une vingtaine de personnes ont été tuées et le bâtiment à moitié détruit ${ }^{68}$.

Es interesante notar que, aunque se trataba de traducciones, ningún telegrama indicaba su fuente o su texto de origen.

La ciudad de Tacna cayó en mayo de 1880:

L'armée chilienne s'est emparée de Tacna après une lutte sérieuse capturant huit canons et faisant un certain nombre de prisonniers. Les troupes chiliennes marchent sur Arica». Effectivement, cette dernière ville tombe en juin: «Rio de Janeiro, 14 juin. Des avis de Valparaiso confirment que la ville d'Arica, a été prise d'assaut le 7 juin par les Chiliens et ajoutent que la garnison a été faite prisonnière. La corvette Péruvienne Manco Capac a été coulée.

Como ocurre en todos los grandes eventos que tienen lugar a una distancia considerable, las noticias falsas no tardaron en surgir sin que se conociera su procedencia. La labor agenciera sufrió por esta situación:

68 «Perú: La Guerra del Pacífico. Un telegrama de Buenos Aires, fechado el 23 de enero, anuncia que la alianza entre el Perú y Bolivia ha sido anulada. Se informa que, en Valparaíso, el 27 de enero, unas granadas han explosionado en el arsenal de esta ciudad. Una veintena de personas han sido asesinadas y el inmueble está semidestruido». 
Nous avons aujourd'hui été assaillis de réclamations au sujet des nouvelles de Tacna publiées par notre Agence, à Lisbonne et Porto, qui sous la date de Valparaiso 31 mai annonce que les Chiliens ont été mis en déroute et que les alliés [péruviens et boliviens] sont entrés à Tacna. Nous supposons, cher Mattos, que ces nouvelles et un autre télégramme de Buenos Ayres mettant en doute les précédentes nouvelles qui annonçaient la capture de Camperos ne vous sont pas arrivées par l'une de nos agences en Amérique [du] Sud, sans quoi vous nous les auriez certainement télégraphié, mais alors, pourquoi avez-vous publié ces démentis sous le nom de l'Agence Havas et avez-vous donné un démenti aux dépêches de nos agents? Quelle est l'origine de ces nouvelles et si vous aviez la certitude de leur exactitude, pourquoi ne pas les avoir télégraphié à Paris? ${ }^{69}$.

Los telegramas agrupados bajo el título «La Guerre du Pacifique» de la Correspondance Havas se hacían cada vez más raros. Solo las noticias concernientes al movimiento de barcos y la advertencia de Estados Unidos hacia las potencias europeas de mantenerse alejadas del conflicto eran tenidas en cuenta por la agencia francesa (Díaz Rangel, 1991, p. 81). Para setiembre de 1880, se ignoraba en Europa el resultado de la guerra: «Le bruit court en Europe que la paix vient d'être conclue entre le Chili et le Pérou. Mais nous n'en avons pas eu avis par la voie de Chili-Plata» ${ }^{70}$.

Bolivia se retiró definitivamente de los combates y, al iniciarse 1881, el Ejército chileno invadió Lima, que terminó por capitular. En Gran Bretaña, la invasión fue percibida como el fin de la guerra (Graham-Yooll, 1985, p. 217), pero esta continuó aún en los Andes y en el Altiplano durante dos años más. La derrota de Huamachuco en julio de 1883 puso fin a la conflagración. Havas recibió la información gracias a otras fuentes que nada tenían que ver con su sucursal de Lima. La agencia francesa reclamó esta laguna a su agente en la capital del Perú:

Il est fort regrettable que vous n'ayez pas cru devoir nous signaler la conclusion de la paix entre le Chili et le Pérou. Deux mots auraient suffit. [...]. Il est vrai qu'autrefois, avant que Lima ne soit relié par câble, nous n'avions pas besoin de ces nouvelles, qui nous parvenaient par les États-Unis; mais tel n'est plus le cas maintenant ${ }^{71}$.

69 Archivos Nacionales, 5 AR 59 (1), f. 401. Charles Emard al agente de Lisboa, Franco de Mattos. París, 7 de junio de 1880.

70 «En Europa corren los rumores de que la paz ha sido firmada entre el Perú y Chile. No obstante, nosotros no hemos recibido noticia alguna por la vía de Chile y La Plata». Archivos Nacionales, 5 AR 57 (5), f. 288. Charles Emard al agente de Lima, Norman Evans. París, 5 de setiembre de 1880 .

71 Archivos Nacionales, 5 AR 57 (5), f. 353. Henri Houssaye à l'agent de Lima, Norman Evans. París, 9 de noviembre de 1883 . 
La situación no mejoró con los resultados de la guerra:

Ce malheureux pays nous paraît ruiné pour longtemps par la guerre avec le Chili, et, malgré les perspectives de paix, il est possible que cette situation dure longtemps encore, puisque ces jours-ci nous avons reçu de Buenos Aires une dépêche signée Ocampo pour le ministre du Pérou, commandant de fusils, cartouches et mitrailleuses pour compte du Gouvernement Péruvien. Tout en rendant justice à vos efforts pour maintenir le service, il faudra donc que nous décidions dans un prochain Conseil si nous devons continuer ce service, qui nous donne depuis si longtemps de la perte ${ }^{72}$.

Havas se hallaba frente a la imposibilidad de relanzar el servicio de informaciones y un acuerdo con el Gobierno del Perú parecía alejarse inexorablemente a causa de la situación política caótica. Solo quedaba tratar de aumentar el servicio de privados, pero allí también el porvenir se anunciaba sombrío:

Le service pour le Pérou est rendu impossible pour nous par les tarifs entre Valparaiso et les divers points de la côte péruvienne. Par suite de la nécessité de faire arrêter par Valparaiso les dépêches pour qu'elles soient réexpédiées par vous à Tacna, Arica et lquique, etc., nous sommes forcés de taxer beaucoup plus cher que le câble; de sorte que personne ne se sert de notre entremise ${ }^{73}$.

El anuncio de la paz, en 1883, no trajo los beneficios esperados por la dirección parisina y la decisión de cerrar la sucursal, por lo menos temporalmente, surgió nuevamente:

Des dépêches de Lima de ces jours-ci nous font espérer la cessation des hostilités entre le Pérou et le Chili, et par suite une reprise bien désirable des affaires commerciales. Nous attendrons encore quelques mois avant de modifier votre situation. Toutefois, si une amélioration ne se produisait pas, nous ne verrions guère d'autre remède

72 «Este desgraciado país parece estar arruinado por bastante tiempo a causa de la guerra con Chile. Y a pesar de las perspectivas de paz, es probable que esta situación se prolongue indefinidamente. En los últimos días, hemos recibido de Buenos Aires un despacho firmado por Ocampo como representante del Gobierno peruano pidiendo fusiles, cartuchos y ametralladoras. Aunque reconocemos los grandes esfuerzos que usted realiza por mantener funcionando este servicio, en un próximo consejo tendremos que tomar una decisión con respecto a esta sucursal. Sucursal que nos hace perder mucho dinero desde hace mucho". Archivos Nacionales, 5 AR 57 (5), f. 348. H. Houssaye al agente de Lima, Norman Evans. París, 5 de marzo de 1883.

73 «El servicio para el Perú se ha vuelto imposible debido principalmente a las tarifas exorbitantes entre Valparaíso y las diferentes ciudades de la costa peruana. Como estamos obligados a que la sucursal chilena le envíe los despachos que usted debe transmitir luego a Tacna, Arica e lquique, nos vemos en la necesidad de cobrar más caro que el cable, lo cual ahuyenta a todo posible cliente». Archivos Nacionales, 5 AR 37 (1), ff. 1-2. Charles Emard el agente de Valparaíso, señor Salazar. París, 6 de junio de 1884. 
que de fermer complètement l'agence jusqu'au jour où l'état des affaires devenant meilleur, nous jugerions opportun de reprendre le service $^{74}$.

No obstante, esta decisión fue también difícil de tomar teniendo en cuenta las no menos difíciles experiencias de las sucursales de Para, Bahía y Pernambuco, que habían sufrido malversaciones y bancarrotas. El largo periodo de inversiones en la capital del Perú fue también un elemento a tener en cuenta:

II nous est pénible après huit ou neuf ans d'efforts incessants à Lima, de cesser complètement le service d'autant plus que si les affaires devenaient ensuite meilleures, nous ne serions plus en mesure d'en profiter $^{75}$.

De 1883 a 1884, Lima fue ocupada por el Ejército chileno y, a causa de los pillajes, la ciudad presentaba un aspecto miserable. El Perú salió devastado de la Guerra del Pacífico con sus puertos destruidos y su Marina, mercante y de guerra, aniquilada.

\section{Las consecuencias informacionales de la Guerra del Pacífico}

La sucursal de Valparaíso heredó el lugar que le correspondía a la de Lima al inicio de la invasión agenciera como polo importante de comunicación en la costa del Pacífico. El cataclismo social, político y económico en el Perú influyó de manera negativa en los asuntos agencieros y condenaron para siempre a la sucursal de Lima.

Antes de la guerra, la agencia Havas se contentó, en lo que respecta a las noticias políticas, con tomar las informaciones de otros diarios o corresponsales no agencieros. Durante la Guerra del Pacífico, al contrario, trataba de utilizar a sus agentes en América del Sur para que le comunicaran las noticias sobre este conflicto de forma fluida. Pero no se trataba solamente de desear emplear una red ya establecida para que funcionara en la medida de lo deseado, pues la agencia francesa tenía ciertos límites y carencias profesionales en sus agentes. Estos, en realidad, desconocían el trabajo de «cobertura» periodística y no atinaban a dar el trabajo de reportaje que se espera de ellos.

74 «Las últimas noticias que nos llegan de Lima nos invitan a esperar el cese de las hostilidades entre el Perú y Chile, y, por consiguiente, una mejoría deseable en el comercio local. Vamos a esperar aún algunos meses antes de modificar su situación. Sin embargo, si el restablecimiento tan esperado no llega, nos veremos en la obligación de cerrar definitivamente la sucursal hasta el día en que los negocios retomen su curso normal». Archivos Nacionales, 5 AR 57 (5), ff. 350-351. Henri Houssaye al agente de Lima, Norman Evans. París, 3 de julio de 1883. 75 Archivos Nacionales, 5 AR 57 (5), f. 362. Henri Houssaye al agente de Lima, Norman Evans. París, 15 de mayo de 1884. 
El escaso producto informacional así obtenido motivó que la dirección parisina orientara sus expectativas hacia sus otras sucursales sudamericanas y europeas, como la que existe en Portugal. Asimismo, recurrió a sus aliados Reuters y Associated Press, a las fuentes diplomáticas, a otros órganos de prensa y de información e, incluso, a los agentes de la banca internacional. De todas estas fuentes, los grandes diarios y sus corresponsales particulares fueron los verdaderos ejes de la cobertura de esta guerra. Los puntos de origen de las informaciones fueron, en orden de importancia, los siguientes: Londres, Nueva York (Panamá), Valparaíso (Lisboa), Berlín y Roma. Nada llegó a través de Madrid, a pesar de la comunión de cultura y lengua entre España y el subcontinente.

Existe una dispersión temporal importante de aproximadamente un mes entre el advenimiento de los hechos y su divulgación en la Correspondance Havas, la principal publicación que nos ha permitido analizar el flujo informativo de este estudio. Los suscriptores de esta correspondencia fueron informados sobre la Guerra del Pacífico a través de la rubrica «Dépêches télégraphiques» principalmente. Esta apareció generalmente al nivel de la tercera hoja del folletín, en otras ocasiones en la segunda $y$, sobre todo en las versiones dominicales, en la primera página. Ciertos aspectos de la cobertura agenciera realizada por Havas son dignos de mencionarse:

1. La frecuencia de las noticias no era nada regular (un retraso de un mes, ya lo hemos dicho, existía para cada emisión informativa) y dependía de la «importancia» de los eventos.

2. Los despachos telegráficos describían el hecho bruto, sin comentarios, y eran desarrollados de forma muy sucinta.

3. Se prefería el punto de vista de los intereses extranjeros, principalmente europeos, en el desarrollo de la noticia.

4. La situación política de los países beligerantes era tan importante como los hechos de guerra propiamente dichos.

5. En su deseo de conservar la sucursal limeña a pesar de todo lo que ocurría, los directores de Havas demostraron la firme convicción de permanecer en un lugar muy importante en la costa del Pacífico.

6. Los diarios sudamericanos no constituyeron la principal fuente de información para las agencias.

En cuanto a este último aspecto, la distancia geográfica y, por lo tanto, temporal que separa a América del Sur de Europa no explica el hecho de cierta indiferencia agenciera hacia los diarios sudamericanos. Además de una brecha cultural cada vez más evidente, el investigador venezolano Eleazar Díaz Rangel asegura que la Guerra del Pacífico mostró la situación 
precaria de la mayor parte de los países en cuanto al desarrollo de las redes y de los contenidos de sus informaciones. Este autor afirma que, aparte de la prensa chilena, que contaba con corresponsales al interior de su Ejército, los periódicos de países como Argentina, Brasil y Uruguay recibieron, tardíamente, la mayor parte de sus noticias de fuentes europeas. Estas últimas fueron generalmente restringidas y expresaban poco los verdaderos intereses del subcontinente en materia de información ${ }^{76}$.

En relación con la distancia cultural que separa ambos continentes, es cada vez más evidente que la influencia cultural francesa en América del Sur tiene ya pocas décadas por delante. No obstante, fue gracias a ella que América del Sur empezó a participar en un circuito internacional de noticias no solamente en tanto receptora de informaciones, sino también como productora de eventos dignos de suscitar el interés de un público europeo ávido de noticias de los «países nuevos».

\section{Contribución del autor}

Rhoda Desbordes Vela ha participado en la concepción del artículo, la recolección de datos, su redacción y aprobación de la versión final.

\section{Fuente de financiamiento}

Autofinanciado.

\section{Conflictos de interés}

La autora declara no tener conflictos de interés. 


\section{REFERENCIAS BIBLIOGRÁFICAS}

Ahvenainen, J. (2004). The European Cable Companies in South America: before the 1st World War. Helsinki: Academia Scientiarum Fennica, 2004

Bethell, L. (Ed). (1995). The Cambridge History of Latin America. Vol. XI: Bibliographical Essays. Cambridge: Cambridge University Press.

Brot, I. (1969). Les archives de l'Agence Havas: branche information conservées aux Archives Nationales (5 AR). París: Services d'Editions et de Vente des Publications de l'Education Nationale.

Boyd-Barrett, O. y Palmer, M. (1981). Le trafic des nouvelles: les agences mondiales d'information. París: Alain Moreau.

Desbordes, R. (2005). Migrations et réseaux d'information au XIXème siècle: Les agences Havas-Reuter en Amérique du Sud, 1874-1876. Amérique Latine Histoire et Mémoire. Les Cahiers ALHIM, nro. 8. Recuperado de http:// alhim.revues.org/index412.html

Desmond, R. W. (1978). The Information Process: World News Reporting to the 20th Century. lowa: University of lowa Press.

Díaz Rangel, E. (1991). La información internacional en América Latina. Caracas: Monte Ávila.

Girault, R. (2004). Diplomatie européenne: nations et impérialismes, 18741914. París: Payot.

Graham-Yooll, A. (1985). Pequeñas guerras británicas en América Latina. Buenos Aires: Legasa.

Jones, C. A. (1979). The British Investor and the London Press Coverage of Argentine Affairs, 1870-90. Cambridge: University of Cambridge, Centre of Latin American Studies.

Lefebure, A. (1992). Havas: les arcanes du pouvoir. París: Grasset.

Palmer, M. (1983). Des petits journaux aux grandes agences: naissance $d u$ journalisme moderne, 1863-1914. París: Aubier.

Rantanen, T. (1990). Foreign News in Imperial Russia: the Relationship between International and Russian News Agencies, 1856-1914. Helsinki: Suomalainen Tiedeakatemia, p. 13.

Read, D. (1999). The Power of News: The History of Reuters. Oxford: Oxford University Press, 1999.

Stone, M. (1921). Fifty Years a Journalist. New York : Doubleday. 